ORIGINAL RESEARCH ARTICLE

\title{
Culture Clash: Shona (Zimbabwean) Migrant Women's Experiences with Communicating about Sexual Health and Wellbeing across Cultures and Generations
}

\author{
Tinashe Dune ${ }^{1^{*}}$ and Virginia Mapedzahama ${ }^{2}$
}

Western Sydney University, School of Science and Health \& Centre for Health Research, Campbelltown, Australia; University of New England, Collaborative Research Network for Mental Health and Wellbeing - Sexuality, Identity and Social Exclusion, Armidale, Australia ${ }^{1}$; Western Sydney University, School of Science and Health, Campbelltown, Australia \& University of Sydney, Sydney Nursing School, Sydney, Australia ${ }^{2}$

*For Correspondence: Email: t.dune@westernsydney.edu.au; Phone: +61 242603655

\begin{abstract}
This paper discusses the influence of cross-cultural modes of communication on perceptions of sexual health and wellbeing for Shona (Zimbabwean) women living in Australia and their children. Data was collected using focus groups in South Australia with fourteen women, between the ages of 29 and 53. Transcripts were analysed thematically. The women primarily constructed sexual health and wellbeing in customary Shona ways, which not only maintain secrecy about sexual health and wellbeing discourse, but also prohibit parents from talking to children about sexual health as such talk is reserved for particular kin and nonkin relationships. These constructions however became more fluid the longer the women resided in Australia. For these women the notions of sexual health and wellbeing are a negotiation between Australian constructs and those from Shona culture, especially when applied to their children. This research highlights the potential influence of various cultural world views on sexual health communication among African migrant women and their children and questions the appropriateness of sexual health and wellbeing campaigns and their responsiveness for cross-cultural youth. (Afr J Reprod Health 2017; 21 [1] : 18-29).
\end{abstract}

Keywords: Africa, cross-cultural, Australia, intergenerational, sexual health, intercultural communication

\section{Résumé}

Cet article traite de l'influence des modes de communication interculturels sur les perceptions de la santé sexuelle et du bien-être des femmes Shona (Zimbabwéennes) vivant en Australie ainsi que leurs enfants. Les données ont été recueillies en utilisant des discussions à groupes témoin en Australie du Sud avec quatorze femmes, âgées de 29 à 53 ans. Les transcriptions ont été analysées thématiquement. Les femmes ont principalement construit la santé sexuelle et le bien-être dans les méthodes coutumières de Shona, qui non seulement conservent le secret sur la santé sexuelle et le discours sur le bien-être, mais interdisent également aux parents de parler aux enfants de la santé sexuelle car les discussions sont réservées aux relations parentales et nonparentales particulières. Cependant, ces constructions sont devenues plus fluides le plus longtemps que les femmes résident en Australie. Pour ces femmes, les notions de santé sexuelle et de bien-être sont une négociation entre les constructions australiennes et celles de la culture Shona, surtout lorsqu'elles sont appliquées à leurs enfants. Cette recherche souligne l'influence. (Afr $J$ Reprod Health 2017; 21[1]: 18-29).

Mots clés : Afrique, cross-culturel, de l'Australie, intergénérationnels, la santé sexuelle, la communication interculturelle

\section{Introduction}

Communicating effectively about sexual health is a pertinent issue that has been gaining increasing global attention. This attention is "partly based on concern about the high contribution to the global burden of disease of risks arising from unsafe sexual practices"1. In Australia, for example, this concern has led to the focus on the importance of cultural appropriateness when communicating to young people about sexual health. Yet sexual health and wellbeing are taught to young people through Eurocentric, biomedical frameworks of sexuality and health that construct health and humans as sexual agents within an individualist society $^{2}$.

Australia's population is increasingly multicultural. According to the Australian Bureau 
of Statistics ${ }^{5}$ over a third of Australians were born overseas and $50 \%$ of Australians have at least one parent who is a migrant. In such a multicultural context therefore, messages about sexual health and wellbeing must necessarily adapt to appreciate the potential influence of cross-cultural constructions of sexuality. This is particularly poignant for 1.5 generation (children born in one country who then migrate to another before adolescence) and second generation (children born in their parents' adoptive country) migrants whose parents may hold cultural world-views and values about sexuality and sexual health that may differ significantly to the Eurocentric, biomedical model dominant in Australia. For these migrant (diasporic) youth it may be very confusing to receive one message about sexual health and wellbeing at home and yet another at school and/or from media ${ }^{6}$. In order to ensure that needs of 1.5. and second generation migrant youth are being met with appropriate education and services it is important to understand how sexual health and wellbeing are constructed and communicated from their migrant parents' perspectives to identify areas where their parents' cultures and 'host cultures' support one another or where they clash.

Not surprisingly however, much of the literature on sexual health communication/education in Australia has tended to focus on the message itself (i.e., what to communicate, and how to communicate it), neglecting critical interrogations of how individuals (in particular, parents) talk about own experiences, perceptions and discomfort when communicating about sexual health to their children. Even when the focus is on parents' discomfort, it is aimed at 'educating' them on how to be good sexual health communicators, again, focussing on the content not the deliverer. What happens then, when this expectation to communicate about sexual health is cast on migrant parents whose world-view about sexual health is informed by cultures whose prescriptions about sexuality are that parents cannot (and should not) communicate about sex, sexuality and sexual health with their children? If Makaudze ${ }^{3}$ is correct in observing that "the way people behave or approach life is mainly guided by how they have been brought up to conceptualise it", then how do such migrant parents, brought up to understand the role of sexual health education as reserved for very specific kin and non-kin relations experience communication about sexual health with their children in cross-cultural contexts?

In the Shona culture, the focus of this paper, only certain relatives discuss sexuality matters with young people "in a culturally relevant manner [these] are: the father's sisters, married or not, called vana vatete [aunties], and their husbands, called vana babamukuru and the mother's brothers, vana sekuru [uncles]", Informed by the questions above, this paper centres the voices of Shona (Zimbabwean) women to address the gap in knowledge about cross-cultural sexual health communication experiences of migrant mothers in Australia. We chose to explore the experiences of these women as they are a significant source of cross-cultural and diasporic data on sexuality as many have experienced how messages (and their dissemination) about sexual health and wellbeing have shifted over time. Although such a shift happens over decades within one society or culture, for migrant families such a shift can literally occur overnight. While we acknowledge the importance of the influence of communication with peers, healthcare providers, teachers, and the media on sexuality and sexual health knowledge, it is beyond the scope of this paper to engage in detailed or even contextualising discussions of these $\mathrm{e}^{7-10}$.

For the Shona people the acceptable "system of sexuality revolves around marriage with its emphases on reproduction and descent"11. This is to say, Shona teachings about sexual health and wellbeing occur simultaneously with teachings about the centrality of marriage for VaShona (Shona peoples). Sex is something that should occur only within the boundaries of socially approved heterosexual marriage, and when it does, it should only be for either procreation (especially for women), and or for male gratification (i.e. the 'good wife' provides sex-on-demand to her husband). Women are taught to never express interest in sex otherwise she risks being labelled as one of 'loose morals', thus bringing shame upon her family. As Kambarami ${ }^{12}$ notes:

In the Shona culture, once a girl reaches puberty all teachings are directed towards 
pleasing one's future husband as well as being a gentle and obedient wife. Her sexuality is further defined for her, as she is taught how to use it for the benefit of the male race

Moreover, there is what Mudavanhu ${ }^{13}$ calls a "sexual secrecy motif" underpinning VaShona conceptualisations of sex, sexual health and sexuality. In other words "sex is a sacred phenomenon and it is not to be talked about but acted. If talked about, it loses its power. This is why sex will be preferred in darkness". Mungini and Matereke ${ }^{14}$ also clearly articulate that,

Among the Shona, the subject of sex is shrouded in secrecy. It is taboo for anyone to pontificate on issues of sex. Consequently, there are people who are regarded as the only ones capable of addressing the issues of sex depending on the nature of the relationship between the teacher and those who are taught. Culturally, parents are not at liberty to discuss issues of sex with their own children. Instead, people regarded as appropriate such as aunts and uncles are supposed to take a lead in talking to the young of their own lineage in this area

If this is the cultural context of sexual health that Shona women were brought up in, then we contend that they may experience a clash of culture when living diasporic lives in Australia where cultural messages about sexual health centre the individual as a cultural being.

Suffice to acknowledge here (as some may argue), that "today's Shona [woman] is in fact, more of a product of the colonial (Western) tradition than [s]he is of genuine African tradition",3, and that as cultural beings: Shona women in Australia "survive [...] [some] form of hybridisation-implying the mixing of [Shona] cultures and [Australian] cultures to form a more unified way of life" ${ }^{14}$. That is, Shona culture is increasingly being influenced by other cultures. Nevertheless we argue that it still functions within a communal system whereas Australian culture for example, tends to function within an individualist one $^{12}$. This fundamental cultural difference is replicated in the ways in which topics on sexual health and wellbeing are communicated to youth ${ }^{8}$. While Australian models expect discussions about sexual health and wellbeing to be generated from one's parents, the Shona model removes this potentially uncomfortable scenario. Shona people may do this in an effect to eliminate perceptions (from both parent and child) of judgement and resistance, when topics of sexual health and wellbeing are discussed ${ }^{17}$. However, once families move out of Zimbabwe there are no or few aunties and uncles or older cousins to relay this information to the next generation ${ }^{15}$.

To address issues of hybridity and potential culture clash in this regard, peer-led ${ }^{18}$ and community-based programs like Red Aware run by the Youth Empowerment Against HIV/AIDS (YEAH) help migrants learn and communicate about sexual health and wellbeing. The Red Aware campaign aimed to "empower young Australians to take action and think about sexual health and get informed, start a conversation about sexual health and take positive action to prevent the spread of HIV and other STIs"19. Although a powerful and impactful education strategy the majority of such programs for migrants are targeted at those with low health literacy, presumed to be those entering Australia via refugee or humanitarian pathways. Considering that such migrants make up less than $5 \%$ of all migration to Australia, according to the Department of Immigration and Border Protection $^{20}$, there is a much larger cohort of skilled migrants $(67.7 \%)$ who are likely to be health literate and may thus believe that such programs are not for them. For instance, according the Australian Bureau of Statistics ${ }^{21}$ "one-third of people born in a country other than Australia had adequate or better health literacy when tested in English compared with $43 \%$ of people who were born in Australia." Without an understanding of how various migrant groups, from various migration pathways, construct, understand and communicate about sexuality, sexual health and wellbeing programs aimed at parents and youth may meet resistance from or prove irrelevant to people from some migrant backgrounds. Further, such attempts may cause confusion as to which model should take precedence - one's (and likely 
communal) values or those of the host society thereby reinforcing the original culture clash.

\section{Positioning the researchers}

Before engaging a detailed discussion of the findings of this study, it is important for us to discuss our own positioning as researchers in relation to this study. We are migrant Shona women living permanently in Australia and as such, we share some similarities of experiences with the group we research, for example: like them, we are mothers raising cross-cultural (second generation) Shona children in Australia. As such, while this study arises out of, and addresses a significant gap in research into crosscultural communication about sexuality and sexual well-being (as elaborated on in the introduction), "our choice of research topic as well as our analytic concern for this research did not arise out of a mere naïve curiosity"22. Rather, it is informed by and rooted in our own experiences as Shona migrant mothers. Still, it is important for us to:

"claim ourselves as situated rather than detached researchers ... [and] knowing subjects who 'see the world from specific locations, embodied and particular, and never innocent' [Rose, 1997, p. 308]

Hence our knowledge production is a 'partial perspective' (Haraway, 1991, p. 183) located in our own positionality as black diasporic Africans in Australia ${ }^{23}$. As knowing and situated subjects therefore, our discussions in this paper are also motivated by the quest to centre the [unique] voice African women in narratives of cross-cultural parenting/communication in Western contexts.

\section{Methods}

The focus groups were conducted in both Shona and English. This strategy was highly relevant as Shona people switch between English and Shona within their day-to-day dialogue ${ }^{22}$.

\section{Study design}

Given that the study was interested in in-depth explorations and understandings of Shona women's constructions of sexuality, it necessarily engaged a qualitative design utilising focus group interviews. This method has an advantage over the one-on-one interview in that it allows interviewees to respond or behave in unanticipated ways, thereby helping to generate new hypotheses ${ }^{24}$. It also offers more scope for the exercise of intuition, helping to provide richer information, particularly information relating to emotional processes and inner reasons. In addition, it inhibits other group members from exaggerating: "it is quite easy to lie, boast about or exaggerate an issue if one is alone with an interviewer, but the person becomes guarded and circumspect if he/she knows that other group members can cross-check their experiences against his/her statements" ${ }^{24}$. Data collection was conducted in August 2012 in Adelaide, South Australia and consisted of fourteen women across four focus groups. The focus groups included between four and five women in each and took from two and a half hours to just over four hours each to complete - more time than initially predicted. We did not organise the focus groups according to age, choosing instead to include a mix of age groups (see below for participant age range) in order to facilitate diversity of opinions based on age.

Focus group discussions explored a broad range of concepts including: 1) what it is like being a Shona woman in Australia versus Zimbabwe (cross-cultural understandings of gender), 2) how the women felt about how their bodies looked, were perceived and worked over time (embodiment), and 3) how the women experienced sexually intimate relationships (intimacy, embodiment, sexual function/performance, gender) including their role in sexually intimate relationships and how has their role changed (if at all) since being in Australia. In order to get at the core concepts of sexuality, as understood by the Shona migrant women, the researchers, both Shona migrant women themselves, deconstructed and adapted concepts of sexuality (in relation to embodiment, intimacy and gender). In doing so, the researchers translated as many words and terms as possible into Shona terminology. On occasion many words denoting whole concepts like sexuality, embodiment or intimacy did not have an equivalent and/or succinct Shona translation. The 
current paper will specifically address and present data pertaining to the third topic discussed in the focus groups.

\section{Sample}

Purposive sampling resulted in a sample of fourteen women, between the ages of 29 and 53 . Notably, all but one woman had completed a tertiary qualification and all were employed professionals. All the women had children and the majority had three children. All but one participant had been married, three of whom had divorced or separated from their partners and another woman was widowed. Ten of the women were 40 years of age or older and all had migrated to Australian within the last 15 years (between 1999 and 2008). All had migrated to Australia under the skilled migration pathway (either as primary applicant or as dependant), and the reasons for migration were varied with the majority being linked to the perception of better opportunities available in Australia.

\section{Recruitment}

Purposive sampling was used to recruit participants. This strategy is most useful when researchers seek in-depth understandings from knowledgeable 'experts' in the issue/topic under enquiry $^{26}$. In these cases it is more important to talk to people who can provide the most useful information about the topic of interest than it is to find a group who is 'representative' and from which wider generalisations can be made. Participants were recruited via free plain-English advertisements through Mapedzahama's existing networks with the South Australia Zimbabwe Association, a community organisation whose membership consists of Zimbabweans (including Shona peoples) living in South Australia where the research was conducted (http://www.communitywebs.org/SAZimbabweAs soc/index.html). We also employed convenience sampling to draw women from our personal contacts.

\section{Data analysis}

The data were analysed for themes by identifying topics and substantive categories within participants' accounts in relation to the study's objectives. In addition, Nvivo 10 was used to ascertain topical responses and emergent substantive categories, inductively coding particularly for word repetition, direct and emotional statements and discourse markers including intensifiers, connectives and evaluative clause ${ }^{25}$. The focus groups were first transcribed in Shona and English (wherever either language appeared). For ease of analysis and accessibility the transcriptions were then fully translated into English. The results section features a mixture of English as it was spoken and English following translation. As a result the women's comments may seem grammatically incorrect or disjointed when presented in this all English format.

\section{Ethical consideration}

Ethics approval for the study was granted by the University of New England's Human Research Ethics Committee. All participants were provided with Participant Information Sheets and encouraged to ask questions to clarify any aspects of the study. All the participants then provided their voluntary written informed consent by signing the study Consent Form and giving it to the researchers.

\section{Results}

The data from the focus groups produced rich and interesting insights about how and what Shona migrant women communicate in regards to sexual health and wellbeing to their children. The following section provides examples of how these women experience communicating about sexual health and wellbeing not only across cultures, but also across generations. Analysis revealed the following themes: Source of Knowledge, Restrictions to Imparting Sexual Knowledge, Communication Facilitators, and Message Content.

\section{Source of knowledge}

As mentioned above, in the Shona context mothers are not expected to be the source of sexual health and wellbeing knowledge for their own children. As such, women highlighted the importance of other familial relationships with regard to 
acceptable paths of sexual communication and imparting of knowledge.

V3: But then in that environment where there is no Aunt, there is no grandmother, you have to sort of talk about those things.

V2: So, as she says that she talks to her son or her children, I cannot say it is me.

Interviewer: So it is a personal thing? (They all agree - umm umm)

V3: So you have to get someone else to talk to them.

V2: Myself, I think our culture was very rich in a way because sometimes when you talk about such things it is going to be somebody whom you are relaxed with and you know there is no barrier of that respect. And as a result, if the mother wasn't involved per se, you could still maintain that respect between the mother and daughter where as if it is Auntie or whatever it can be a jocular thing she is freer to say whatever she wants and you are also free to say to that person and...

V3: I am also saying even though I have said it to my boys, I still feel I need to find another person that can talk to them in a more detailed way

This excerpt not only highlights the challenges and discomforts of having "the talk" for Shona women, but also where and when knowledge could be gained if not from one's parent(s)/relatives. Interestingly however, we also found that while communicating sexual knowledge was contentious within Shona culture, the women also noted that as Shona girls growing up in Zimbabwe they also acquired this knowledge through other means (albeit with a Western outlook/influence).

V3: Yes, you get into a marriage or you get into a relationship and you do not know what orgasm is.

Facilitator 1: How do you learn about that then?

V2: You hear people talking about it.

V3: Or when you start reading. Like reading Mills \& Boons and reading whatever, then you start saying "oh this happens, oh".
Facilitator 1: So, those are English things. (All answer) Yes, yes.

V3: So, you know through reading.

Facilitator 1: Western things or things that are coming from Zimbabwe?

(All answer) Yes, yes.

With others who did not have the option of family to communicate with their children there was confusion about when to begin discussing sexuality with their children and the repercussions of leaving the conversation too late.

V2: But what we are also saying is at what age then should they start doing this? Like she mentioned for the girls from the moment you start menstruating you are already developing.

Facilitator 1: Or before that actually...

V2: So, when are we saying they can start exploring?

Facilitator 2: When they start running (experiencing) around with different boys/men?

V2: Yes, but it is not good.

Facilitator 2: Is that when you are supposed to say something?

V2: That is when you are supposed to be involved sexually when you still have those little hormones active. (Laughing)

Facilitator 2: That is when you are supposed to start teaching the children?

V3: I thought when she tells me "I have got a boyfriend" that is when I will talk to her. Because I am thinking maybe if I start talking to her it is like I am saying you should be having a boyfriend by now.

V2: I think this is when a lot of people's downfall happens, therefore, this is when you are supposed to be actively involved, but I think that is when the downfall comes, when you are quick, unfortunately that is how it is your downfall

This excerpt highlights that some women felt it best to start communicating about sexuality with children well before puberty or they begin exploring their sexuality in order to avoid having to deal with unplanned pregnancy, STIs and sexual coercion. Whilst it is acknowledged that discussing 
sexual health and wellbeing with one's children is best done sooner rather than later the women compete with the difficulty of starting early and the "downfall" as a result of a quick conversation had too late. Yet, there seemed to be further sociocultural phenomena which restricted ease in communication.

\section{Restrictions to imparting sexual knowledge}

The majority of the women, who had marital, family and professional experience with sexual health and wellbeing, had a wealth of knowledge on the topic. However, when it came to their own children they did not feel it appropriate to begin that discussion. We found that the women acknowledge the influence of Shona culture in which Christianity plays a large part in mediating sexual behaviour. Take one woman who knew a great deal about sexual behaviour and pleasure which she imparted to her cousins, but not her daughter:

Facilitator 1: So, then you are imparting that knowledge to her [her daughter]

V3: To her? Not yet.

Facilitator 1: How old is she?

V3: She is 22.

Facilitator 2: So, how come you are not imparting that? Because under Western culture she would be someone you know (interrupted)...

Facilitator 1: (Interrupting) sexually matured.

V1: We are torn in-between cultures. You can't!

Facilitator 1: Why?

V1: Especially with my background

Facilitator 1: What is your background?

V1: The Shona background. People are so maybe churchish and they don't.

Facilitator 1: Conservative?

V1: Exactly, so mom never talked about it

The excerpt above highlights the difficulty most of the women encountered when communicating and imparting knowledge about sexuality: that it conflicted with traditional and religious conventions. In line with this some women expressed their apprehensions about what might happen if they imparted sexual knowledge to their children and their decision to withhold information.

V2: I think in a way if they knew about this information then they will want to explore it.

Facilitator 1: It is like an endorsement?

V2: So, you do not know how to draw the fine line whether to say you can still do it and be safe or better to shut it out until the right time to; so we just shut it down

\section{Communication facilitators}

Although adherence to Christian principles stood in the way of communicating about sexual health and wellbeing, women who attended Church regularly found that in that context, sexuality could be discussed with their children in a way that aligned with their Shona identity and promoted a cross (and multi) cultural framework of discussing sexuality.

V4: You show interest, and ask what has been said; like us we are lucky that we are going to Church; therefore, at Church they are taught that. Therefore, we encourage our children to be taught, especially now that they want; they go by stages, so, they want to be taught.

Facilitator 1: Why is it important to have sex education in your opinion?

V4: Myself, I think it is important that they have sex education because when they are taught by someone from our Church instead of getting this information from somebody else, because definitely the team will educate them, but in a way they know better than us. Of course, they see all that on $T V$, but if they hear from someone of our own telling them, it is better than getting it because the information will always come.

Facilitator 1: And that information is not always right it is just (interrupted)

V1: (Interrupting) and these people that know what they do in real life. It is acting. To them, they are at work

This means of communicating about sexual health and wellbeing can be informed by community and 
peer-led interventions as discussed earlier. We also found a resourcefulness in this community wherein they drew upon the strengths of existing structures within their communities to deliver sexual health and wellbeing messages in ways that mimicked the structures in the Shona culture and which are therefore acceptable and welcomed by the group. For example, the church community took on the 'role' of vanatete (aunties) and vanasekuru (uncles):

Facilitator 2: Therefore, at Church they are being told by other Shona Zimbabweans.

(All agree) Umm; yes.

Facilitator 2: So, would you say you are doing your own community that you are creating, that Aunt you were talking about. (All agree) Umm; yes.

Facilitator 2: So, you select someone who acts the role of Auntie?

(All agree) Umm; yes.

V1: Even in Zimbabwe there were no Aunts; therefore, Church is the one that was doing...

V2: It is not like a community because ours is a multicultural, so it does not matter whether an Australian or an African, as long as they are in that Church community, they are just taught.

V1: Whether whites know that you can do anything, they are taught the Church way, but it is their own choice to say A, B, C is what we want

The significance of the Church in this context, as well as the Shona women's utilisation of it as a medium through which sexual health education is conveyed to their children lies in the central role the church has held in regulating sexual behaviour in VaShona since its introduction to Shona culture during British colonial rule. While one can argue that this reliance on the 'church' community in Australia points to continuities and postcoloniality, we need to clarify here that the churches the women refer to (and attend) are African Pentecostal organisations emerging in Australia. These churches have been established primarily for the gathering of Zimbabwean migrants by the migrants themselves. Hence they are as much about shared Shona values as they are about shared Christian values.

\section{Message content}

While the focus of this paper is not on the content of sexual health messages, it is nevertheless important for us to briefly discuss how the women talk to their children about sexual health when they have no choice but to do so themselves. Such a discussion would necessarily involve an articulation of message 'content'. Although conversations may have been difficult and/or culturally foreign the women found ways to communicate issues about sexual health which they perceived as important. For instance, some women decided to impart information in a way which they felt acknowledged the reality of psychosexual and physiological development of sexuality within their children.

Not block them, not blocking like I said when I am teaching my daughter, I actually say, yes you are going to feel you know, to be tricked like they would say when we are growing up. Boys used to say that she has been around with many men (prostitute)... what reaction does that girl have? Do you think she won't feel anything? But, what we are saying is if she takes it to the next step, then what is going to happen? Because those developments, they happen. We have to acknowledge that we have those feelings

Although the above quote acknowledges sexual feelings within young people it is also problematized in the perception of girls with those feelings, and act on them, are perceived as prostitutes. This may be why other women modified the content of the conversations preferring to wait until their child 'came of age' before including more information.

V2: Like now I encourage her not to have a boyfriend until she is of age. I might have done it but I say to her look.

Facilitator 1: So what is the age?

V2: Well I say to her like when you were about to have a baby you would be able to 
take care of it. If you look at it right now you are going through body changes hormonal changes, your body is changing. Facilitator 1: How old?

V2: 16, she is 16

Facilitator 1: So how old do you think?

V2: Well in my opinion if she can hold herself, if she has built her career, if she... Facilitator 1: So not that age anymore?

V2: Well the problem is they are so much exposed to sex, they don't know where to stop. And then the next minute you have teenage mothers.

Facilitator 1: So do you tell her about condoms, about, what do you tell her?

V2: Abstinence - that is what I tell her, to say "don't". If you have a boyfriend the next minute is you are holding hands, you are touching your boobs and where it ends up I don't know and kissing at that.

(they all talk on top of each other's voices, laughing)

In order to mediate a child's natural inclination to explore their sexuality the women imparted expectations of how they perceived their children should navigate their sexuality. All the women agreed that in Shona culture if one is interested in sexual relations they are expected to first be married. This expectation did not change for their children. When asked about how they would explain sex to their child one women responded with the following:

Do you want to go and get married, my child?

When discussing how children were expected to translate their parent's messages about sexuality into controlling their sexual desire/impulses the women indicated various strategies.

It is by grace [of God]. God made it as a natural thing. Can I teach you how to feel? When you have education you can choose [to control yourself].

And teaching your child to prioritise...Therefore, let us face it, you have parents who are very rich, they could afford you know, to financially help to look after that child [unplanned pregnancy], but you know, but what we are saying is for that young girl is she emotionally, mentally and or even physically fit to have another, to have a baby and be a mother because it is not just a question of having a baby.

These quotes show that the women perceived that help with the suppression and mediation of one's sexuality could be found through faith, education about sexuality and finally the ability to prioritise. The last quote also brings socioeconomic wealth into the discussion and seems to imply that people with money may not be so worried about teenage pregnancy because they can afford to raise the child. The topic of resources is an important one in the context of Shona women as they are likely to have encountered, directly or indirectly, the effect that poverty has on girls and women - especially unwed single mothers - during their time in Zimbabwe. Considering the social, cultural and psychological competition between educating one's children and leaving them to figure it out (and yet hoping that they won't) the women gave some insight into what they perceive young people do or should know.

\section{Discussion}

The investigation aimed to better understand the role of cross-cultural understandings of sexuality and sexual wellbeing for Shona (Zimbabwean) migrant women that may be relevant to African migrants more generally. Through this research an additional key finding emerged which highlighted the importance and means of cross-cultural and cross-generational communication about sexuality. For the women in this study the challenges of migration were also manifested in their transfer (or lack thereof) of sexual health and wellbeing knowledge to their children.

Our finding that the women found navigating differing sexual health and wellbeing communication pathways challenging in itself is not a new phenomenon. Much literature has discussed the experiences of parents in other contexts (including in Australia) who struggle to have discussions about sexuality with their 
children $^{29,30}$. What is significant about the finding, and potentially applicable to African parents more generally, is the societal expectation about who should participate in conversations about sexual health and wellbeing with young people. In Australia, the societal expectation is that parents will communicate with their children about sexuality $^{31,32}$. For instance, research ${ }^{33,34}$ indicates that parents in countries like Australia are cognisant of the expectation of parental involvement in the sexual health and wellbeing education of their children. Whether parents are comfortable having such conversations or are knowledgeable about the topic is another issue. Conversely, in many African cultures parents are not expected to be involved in their children's sexual health and wellbeing education ${ }^{17}$. While we acknowledge that intergenerational culture clashes and conflict can result from differing messages about sexual health and wellbeing our research found that it may not only be the messages, as often assumed, which ultimately result in a cultural clash. Another layer of complexity may be the means through which the messages are expected to be delivered.

This may be why the women felt most comfortable with members of their church teaching their children about sexual health and wellbeing as it mimicked the role fulfilled by a close family member who shared their morals and attitudes about sexuality. The church may have also been most comfortable as it espouses an abstinencebased approach to sexual behaviour that mirrors the message the women endorsed with their children - a perspective supported by a range of African groups ${ }^{7,8,11,12,16,17,25}$. In order to gain parental endorsement of comprehensive sexual health and wellbeing programs future research could investigate individuals or institutions that migrant parents believe they can entrust with their children's sexual health and wellbeing education. This may also include drawing on the strengths of resources aimed at parents to improve sexual health and wellbeing communication with their children. Further practice and research can also be done on the development and impact of peer-led and community based programs which can be embedded into migrant resettlement services or migrant community organisations. Given their focus on migrant health and wellbeing these setting may be most appropriate in creating culturally acceptable and appropriate means of imparting sexual health and wellbeing knowledge which aligns with cultural conventions.

The study has also highlighted key areas which require further consideration and investigation. Most poignantly the participants were all skilled migrants and thus well-educated and many were nurses indicating an extensive and contemporary understanding of sexuality from many perspectives due to exposure to how others navigate relationships and sexual health/wellbeing via patient/client interaction. While these aspects of the sample helped the researchers to identify key concepts in relation to sexual wellbeing across cultures it is not representative of the many nonWhite migrants who may not have high levels of education, who do not speak English with enough fluency to attain mainstream employment, who do not prescribe to Christianity (which is the most popular religion in Australia and is the Eurocentric foundation upon which many Australian systems were historically founded) and are viewed as social outsiders/others by the general Australian public. People in these migrant groups may have less of a cross-cultural view on sexuality and may have difficulty navigating health and wellbeing systems which are Eurocentric and contrary their spectrum of knowledge. Moreover, some of the limitations of this research may arise from those inherent in research in two languages: the 'problem' of translation. These include: lack of translational equivalence (of some words) as well as problems that arise due to "stylistic factors" 27 wherein endings used in some languages to emphasise various phenomenon cannot be translated. For example the prefix "va-"in "vatete" is a reference of respect when talking about 'aunties'. Our literal translation of 'aunties' does not make visible the significance of the prefix, particularly its significance in the context of sex education/talk.

\section{Conclusions}

This research highlights that a better understanding of how sexuality is understood across (and within) cultures highlights the potential limitations of Western expectations of parental involvement in 
their children's sexual health and wellbeing education. Considering that some migrant parents may be stuck on how to communicate such information in ways that are relevant to both their cultural beliefs and multicultural Australian communities' interventions to address these needs are required. In Australia, although there are resources available to assist parents with communicating with their children about sexual health and wellbeing (see for example Planned Parenthood $^{31}$; Better Health Channel ${ }^{35}$ - Sex education - tips for parents) these resources are not directed towards migrants and often do not consider their particular perspectives on the matter. This omission or oversight from Australian programs may leave many migrant parents without support or the opportunity to contribute to such developments. It is therefore important that sexual health and wellbeing communication support be made available to migrant parents who can equip them with tools and strategies to navigate crosscultural and intergenerational variance with regards to discussions, expectations and information ${ }^{36}$.

Multicultural countries can also benefit from research which explores the role of culture in the messages, understandings and constructions of sexual health and wellbeing for 1.5 generation migrants (these are not the conventional first generation migrant, who are old enough to emigrate on their own, nor are they the conventional second generation migrant, the offspring of the first generation migrant born in the country of emigration. This cohort includes people who left their country of origin and migrated to Australia before completing puberty/adolescence). Doing so may highlight key sociocultural areas which young people, who were born into one culture and are, completing puberty in another, believe needs to be addressed for their sexual health and wellbeing being. To that effect African migrant voices and understandings should be included in the development of education and services, the appropriateness and implications of policy, service delivery and health promotion in regards to sexual health and wellbeing.

\section{Contributions of Authors}

Both authors conceived and designed the study; collected and analysed the data; and prepared the manuscript. All authors mentioned in the article approved the manuscript.

\section{References}

1. World health Organisation (WHO). Brief sexualityrelated communication: recommendations for a public health approach. WHO, Geneva 2015.

2. Dune, TM. Constructions of Sexuality and Disability: Implications for People with Cerebral Palsy. Saarbrücken: Lambert Academic Publishing 2012.

3. Makaudze, G. Sex and the female body in Shona society. Journal of Pan African Studies 2015; 7(8): 140-153.

4. Gwandure C. Mubobobo: Women have no sexual fantasies in their sleep. The Open Anthropology Journal. 2009; 2:74-81.

5. Australian Bureau of Statistics. 2071.0 - Reflecting a Nation: Stories from the 2011 Census, 2012-2013. Australian Government 2013.

6. Cha, ES, Kim, KH and Erlen, JA.Translation of scales in cross-cultural research: issues and techniques. Journal of Advanced Nursing 2007; 58(4): 386-395.

7. Mpofu E, Dune TM, Hallfors DD, Mapfumo J, Mutepfa MM, January J. Apostolic faith church organization contexts for health and wellbeing in women and children. Ethnicity \& health. 2011 Dec 1; 16(6): 551-66.

8. Mpofu E, Hallfors DD, Mutepfa MM, Dune TM. A mixed methods mapping of church versus secular school messages to influence sexual decision making as perceived by Zimbabwean orphan girl students. Journal of mixed methods research. 2014 Jun 19:1558689814539394.

9. Dune, T. Experiences of sexual well-being and the yin revolution. In: Fisher F, Faller, P, editors. Yin Rising: The Chinese Sexual Evolution. Granite Bay: Griffin Publishing, 2014

10. Hawkes GL, MacPhail C, Dune TM, Pitts M, Minichiello V. Beyond ageism and sexism: creating their own scripts: some reflections on social media participation by older Australian women. In Reimagining Social Problems: Moving Beyond Social Constructionism: 63rd Annual Meeting of the Society for the Study of Social Problems, August 911, 2013, The Westin, New York at Times Square 2013.

11. Mudavanhu, J. The attitude of the Methodist church in Zimbabwe to homosexuality: Towards a sociosexological theological investigation, The University of Birmingham 2010. 
12. Kambarami, M. Femininity, sexuality and culture: Patriarchy and female subordination in Zimbabwe. South Africa: African Rural Sexuality Resource Centre 2006.

13. Mudavanhu, J. The attitude of the Methodist Church in Zimbabwe to homosexuality: Towards a sociosexological theological investigation. Diss. University of Birmingham, 2010.

14. Mungwini, $P$ and Matereke, K. Rape, sexual politics and the construction of manhood among the Shona of Zimbabwe: Some philosophical reflections. Thought and Practice 2010; 2(1): 1-19.

15. McGregor, J and Primorac, R (Eds.). Zimbabwe's new diaspora: Displacement and the cultural politics of survival (Vol. 31). Berghahn Books 2010.

16. Tambulasi, R and Kayuni, H. Can African Feet Divorce Western Shoes? Nordic Journal of African Studies 2005; 14(2): 147-161

17. Gwandure, $\mathrm{C}$ and Mayekiso, T. Sexual desire and expression among girls in a traditional Shona context. Anthropologist 2012; 14(5): 415 423.

18. Drummond, PD, Mizan, A, Brocx, K and Wright, B. Using peer education to increase sexual health knowledge among West African refugees in Western Australia. Health care for women international 2011; 32(3): 190-205.

19. YEAH. Join Red Aware 2015. Retrieved June $21^{\text {st }} 2016$. Retrieved from: http://www.redaware.org.au/joinredaware/

20. Department of Immigration and Citizenship. Migration programme statistics. Australian Government 2015. Retrieved June $11^{\text {th }}$ 2015. Retrieved from: https://www.immi.gov.au/media/statistics/statisticalinfo/visa-grants/migrant.htm

21. Australian Bureau of Statistics. 4102.0 - Australian Social Trends, June 2009. Retrieved August $18^{\text {th }}$ $2016 . \quad$ Retrieved from: http://www.abs.gov.au/AUSSTATS/abs@.nsf/Look up/4102.0Main+Features20June+2009

22. Mapedzahama, V. Worlds Apart? A Cross-national Comparative Study of Employed Mothers Negotiating Paid Work and Family in Australia and Zimbabwe. University of South Australia: Adelaide 2007.

23. Mapedzahama, V and Kwansah-Aidoo, K. "Black on Black: Insider positionality and the black African migrant research experience in Australia", in L. Voloder and L. Kirpitchenko (Eds), "Insider Research on Migration and Mobility: International Perspectives on Researcher Positioning". London, Ashgate Publishers, 2014, pp. 169-186

24. Obeng-Quaidoo, I. "New development-oriented models of communication research for Africa". Africa Media Review 1987; 1 (2): 51-64.

25. Dune, T, Mapedzahma, V, Pitts, M, Minichiello, V and
Hawkes, G. African Migrant Women's Understanding and Construction of Sexuality in Australia. Advances in Social Science Research Journal 2015; 2(2): 38-50.

26. Tongco, MDC. Purposive sampling as a tool for informant selection. Ethnobotany Research \& Applications 2007; 5:147-158

27. Ervin, S and Bower, RT. Translation problems in international surveys. Public Opinion Quarterly 1952; 16(4): 595-604.

28. Kirkman, M, Rosenthal, DA, \& Feldman, SS. Talking to a tiger: fathers reveal their difficulties in communicating about sexuality with adolescents. New directions for child and adolescent development 2002; 97: 57-74.

29. Riggio, HR., Galaz, B and Garcia, AL. Contraceptive Attitudes and Sexual Self-Esteem Among Young Adults: Communication and Quality of Relationships with Mothers. International Journal of Sexual Health 2014; 26(4): 268-281.

30. Schuster, MA, Corona, R, Elliott, MN, Kanouse, DE, Eastman, KL, Zhou, AJ and Klein, DJ. Evaluation of Talking Parents, Healthy Teens, a new worksite based parenting programme to promote parentadolescent communication about sexual health: randomised controlled trial. British Medical Journal 2008; 10: 337.

31. Planned Parenthood. Talking to Kids About Sex and Sexuality 2014. Retrieved Jan $22^{\text {nd }} 2015$, retrieved from: http://www.plannedparenthood.org/parents/ talking-to-kids-about-sex-and-sexuality

32. The Hospital for Sick Children (SickKids). Sex Education for Children: Why Parents Should Talk to their Kids About Sex 2014. Retrieved Jan $22^{\text {nd }} 2015$. Retrieved from: http://www.aboutkidshealth.ca/En/ HealthAZ/FamilyandPeerRelations/Sexuality/Pages/ Sex-Education-for-Children-Why-Parents-ShouldTalk-to-their-Kids-About-Sex.aspx

33. Jaccard, J, Dittus, PJ and Gordon, VV. Parent-Teen Communication about Premarital Sex Factors Associated With the Extent of Communication.Journal of Adolescent Research 2000; 15(2): 187-208.

34. Wilson, EK, Dalberth, BT, Koo, HP and Gard, JC Parents' perspectives on talking to preteenage children about sex. Perspectives on Sexual and Reproductive Health 2010; 42(1): 56-63.

35. BetterHealth Channel. Sex education - tips for parents 2015. Retrieved June $11^{\text {th }}$ 2015. Retrieved from http://www.betterhealth.vic.gov.au/bhcv2/bhcarticle s.nsf/pages/Sex_education_tips_for_parents?OpenD ocument

36. Ramanathan, V. Acculturation, sexuality and sexual health of Indian migrant men living in Australia. University of Sydney, Faculty of Health Sciences 2013. 